\title{
TEXTOS KA'APOR
}

Etnia Ka'Apor

Os Ka' apor estão localizados no estado do Maranhão falam um língua do tronco tupi-guarani, a população é de aproximadamente 2000 pessoas. ${ }^{1}$ Textos do retirados do livro Ymanihar Panduha As palavras antigas ${ }^{2}$

1. Fonte https://pib.socioambiental. org/pt/povo/kaapor/651

2. Ymanihar panduha: as palavras antigas/ Geraldo Ka' apor...et al. (organização: Mário Alexandre (organização: Mário Alexandre UFMG: SECAD/MEC, 2007.

$34 p$ :il. 


\section{A HISTÓRIA DA ONÇA}

O Ka ápor vai esperar a onça

Quando foi meio-dia, o Ka ápor foi fazer a escada

Ele vai esperar até a lua cheia

Ele vai esprar na flor da faveira

$\mathrm{O} \mathrm{Ka}$ ápor já foi para esperar (a onça)

A onça já chegou a meia-noite

$\mathrm{O} \mathrm{Ka}$ ápor estava esperando no topo da escada

Quando o Ka ápor ouviu um vento barulhento, que levou a onça na flor da faveira

E quando o Ka ápor viu a onça, ele flechou a onça

Ele fechou o takwarp

\section{A-É REHE HAR}

IRAKADJU KA'APOR

Ka ápor a-é ke harõ ta oho

Ka ápor warahy jana rahã a é myta a é mujã oho

Jahy wahu rahã a é harõ ta oho

Jupuy putyr a é harõ ta oho

Ka ápor oho harõ y

Pytu pytep pe a-é uhyk u-wyr

Ka ápor myta ár pe a é harõ y

Ka ápor hendu ywytu tyapuha ke ywytu namõ a-é uhyk u-wyr

Pe a é usak a-é rehe Ka ápor u ý pe a é jyngo

Takwar pe a é jyngo

\section{A HISTÓRIA DO VEADO}

O menino que foi procurer alguma coisa

O menino está indo para a mata

O menino foi para a mata e achou o veado

O menino flechou o veado

$\mathrm{O}$ menino matou o veado com a fleche

O menino partiu o veado

O menino também fez a pêra

O menino trouxe o veado dentro da pêra

O veado está comendo a flor do ipê

O menino já chegou com o veado

O menino deixou o veado perto da aldeia para sua mãe ir buscá-lo

A mãe do menino foi buscar o veado

O pai do menino que moqueou o veado em cima do moquém

A mãe do menino levou o veado moqueado para distribuir na aldeia

É assim que nós, os Ka ápor, comemos o veado

$O$ veado foi caçar o alimento

$O$ veado encontrou o alimento

O veado comeu bem a flor do ipê

O veado também gosta da flor da jarandeira

$\mathrm{O}$ veado também come flor de tauair e a fruta de tatajuba
3. Faveira: árvore leguminisa Takwar: ponta da lança na fleche Contexto: antes do uso da lantern era necessário esperar a lua cheia para caçar uma onça, pois a lua cheia proporciona claridade dentro da mata. 


\section{ARAPUHA REHE HAR}

MARISA KA'APOR

Kurumi riki ma é kekar oho

Ka á pe kurumi oho ixo

Pe arapuha ke kurumi mahem oho

Pe kurumi arapuha ke jyngo

U ý pe riki kurumi arapuha ke jukwa

Pe kurimi arapuha ke mowok riki

Pe kurumi pehir mujã ti

Pehir pe kurumi arapuha ke werur

Tajy putyr ke arapuha u ú ixo

Tajy putyr rehe kurumi arapuha ke jukwa

Pe kurumi arapuha ke muhyk werur

Peja i-te te é riki Kurumi arapuha ke hija uwyr

Pe riki kurumi mãi oho pijãm ti

Kurumi pai riki arapuha ke muka é

Muka étaár pe kurumi mãi muhãi

Aja riki arapuha awa u ú há

Himi ú arapuha awa u ú há

Mahem arapuha himi ú oho

Tajy putyr ke arapuha u ú katu

Iwiri ý putyr ke arapuha u ú riki

Amõ tareka, pimiti putyr riki arapuha u ú ti

\section{A HISTÓRIA DA MACAXEIRA}

A esposa do velho vai levar a macaxeira para casa

Ela carrga bem a macaxeira

Ela foi pelo caminho

Ela não viu a árvore

O toca da árvore furou o pé dela

O pé dela está doendo

A esposa do velho carregou a macaxeira

Ela já chegou na casa dela

O que a esposa do velho trouxe?

Ela já trouxe a macaxeira

A esposa do velho foi para o igarapé

Ela levou a macaxeira para lavar

A esposa do elho não viu aquela coisa

Ela viu o carangueijo

\section{MAKASER REHE HAR}

WA'I KA'APOR

Tamuj rakehar makaser hok pe raho ta

Makaser a'e hupi katu

Pe rupi a'e oho

Myra rehe a'e usak 'ym

Myra ipy ke kutuk

Ipy ahy riki

Tamuj rakehar makaser hupir raho 
Hok pe a'e uhuyk uwyr

Ma' e tmuj rakehar muhyk?

Makaser a'e muhyk werur

Y pe tamuj rakehar oho

Makaser a'e kutuk raho

Ma'e tamuj rakehar usak 'ym

Tame rehe a'e usak 